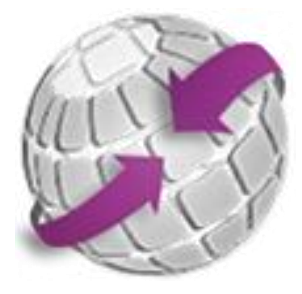

\title{
Application of New Ecological Paradigm on Leisure Activities
}

\author{
Tulsi Paudel ${ }^{1}$, Wen Ya Li ${ }^{2}$ and Yeong Gug Kim³,* \\ ${ }^{1,3}$ College of Business Administration, Kangwon National University, South Korea \\ ${ }^{2}$ College of Hotel and Tourism, Kyung Hee University, South Korea
}

\begin{abstract}
.
These days' environmental friendly activities in various sectors are increasing. In tourism researches there are various studies regarding the environmental concern of tourist and visitors. Trekking is also one of popular tourist activity and which is directly engaged with nature and environment. Environmental pollutions, degradation, climate change, global warming are some of those issues which are most discuses in this modern world. The natural resources in this earth are extensively utilizing by humans. Dunlap and Van Liere (1978) defined the relation between human activity and natural system as New Ecological Paradigm (NEP). The purpose of the study is to investigate trekkers' environmental friendly behaviour. To sum up this study uses NEP for the determination of environmental friendly trekking. The survey was analysed 223 responses which were taken from online sources among trekkers of Republic of Korea. Results are concluded on the basis of statistical analysis using SPSS 24.0 and AMOS 22.0. This research also discusses the empirical implications and limitations of this specific work. Also this study revealed that people have become more concerned about what actions they can take to protect the environment. From this point of view, this study tries to establish environmental attitudes of trekkers using NEP theory.
\end{abstract}

Keywords: Environmental Friendly Behaviour, New Ecological Paradigm, Leisure activities

\section{Introduction}

Numerous research has conducted using NEP as general environmental studies in various populations. Most of past works in tourism researches in NEP are focused on only descriptive studies of tourism NEP scores (Grybovych et al., 2005). Previous researches involving environmental attitudes has primarily focused on (1)descriptive analysis of tourists' NEP scores (Grybovych et al. 2005), (2)the relationship among attitudes toward the environment, 


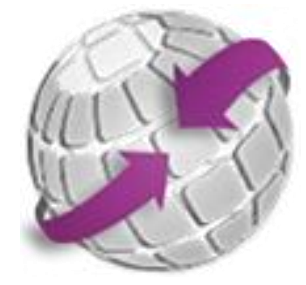

$6^{\text {th }}$ International Conference on New Ideas in Management, Economics and Accounting

\section{France | Paris | April 19-21, 2019}

activities pursued by visitors (Luzar et al., 1995), and their trip and socio-demographic characteristics (Uysal et al., 1994), (3)changes in tourists' environmental attitudes as a result of the implementation of environmental education or interpretation programs (Lee Won-Hee and Moscardo, 2005), and (4)the relationship between tourists' environmental attitudes and their tourism-related environmentally friendly purchasing behaviour (Wearing et al., 2002) or general ecological behaviour (Wurzinger and Johansson, 2006).

However, a recent tendency shows that researchers are increasingly interested in identifying and segmenting eco tourists by their social or environmental attitudes (Formica and Uysal, 2008; Zografos and Allcroff, 2007) or Non-autonomous Bifurcation Theory (NBT) motivation or interests (Biljana, Cornwell and Mather, 2002). The relationship between behaviour and attitude led interest in environmental friendly attitudes as predictors of participation decisions, or actions. Various social psychology literatures on behaviours research has emphasized the role of attitudes as predictors or behaviour, behavioural intentions and exploratory factors of varieties in individual behaviour (Ajzen and Fishbein, 1980; Heberlien, 1989). Although most of the studies focused on environmental attitudes and behaviours these studies only analysed the main socio-economic variables determining environmental attitudes (Buttel, 1987). The Theory of Planned Behaviour primarily not concerned about environmental attributes. Later there has been continues interest on environmental concerned behaviour. Schwartz (1997) argued value of personal norms for pro environmental behaviour.

This study intended to fill blanks in tourism researches where environmentally friendly behaviour and attitudes are key for preserving tourist places and destination. Trekking is directly associated with surrounding and nature and environmentally sensitive. New forms of trekking seeking environment less damage are introduced. This study aims to investigate how people think about environment while trekking. Moreover their behaviours to the environment and nature. The New Ecological Paradigm (NEP) scale is one of the popular tool to determine environmental attitudes and various researches following this tool for their research purposes. In this study also NEP scale is used to examine environmental attitude and worldview to the earth of trekkers. Environmental friendly behaviour is examined throughout the various literatures. The purpose of the study is to investigate trekkers' environmental friendly behaviour. To sum up this study uses NEP for the determination of environmental friendly trekking.

\section{New Ecological Paradigm (NEP)}

Before discussing New Ecological Paradigm there is continuous arguments on values, attitudes, confidences and beliefs felts or adopted in regard to wealth, rapid development and technological achievements which is known as dominant social paradigm was described as the reason for awareness of environmental problems (Dunlap and Van Liere, 1978; Catton and Dunlap, 1980). The significant shift from dominant social paradigm in terms of defining human 


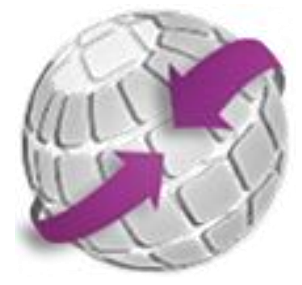

$6^{\text {th }}$ International Conference on New Ideas in Management, Economics and Accounting

\section{France | Paris | April 19-21, 2019}

and nature relationship more effectively to more eco-centric paradigm leads this discussion to the formation of New Environmental Paradigm (Dunlap and Van Liere, 1978).

The New Ecological Paradigm is a developed form of New Environmental Paradigm which is first ever described by Dunlap and Van Liere in 1978. This scale was first designed to measure people's environmental concern using survey instruments. Dunlap and Van Liere (1978) modified Dominant Social Paradigm (DSP) which has 12 items calling anticlinal and made new scale called New Environmental Paradigm. The original New Environmental Paradigm (NEP) scale was criticized by researchers because of its several demerits. To overcome criticism original NEP which has 12 items were revised. Dunlap et al.(2000) revised New Environmental Paradigm adding three items more and named is revised New Ecological Paradigm scale (Table 1). The revised NEP scale has 15 items with eight of the items, if agreed by a respondent agreement to reflect endorsement of the New Ecological Paradigm while agreement with the other seven items represent endorsement of the Dominant Social Paradigm (DSP)(Dunlap et al., 2000).

The NEP Scale has been widely used to analyse and contrast environmental attitudes of different groups (Caron, 1989). The use of NEP scale to determine relationship between environmental attitudes and environmental knowledge also exits in literatures (Arcury, Johnson and Scollay, 1986; Arcury, 1990; Edgell and Nowell, 1989). Furman (1998) factorized NEP statements in three factors as 'balance of nature, limits of growth, and human over nature, whereas in the study by Taskin (2009), modified factors as steady-state economy, Human Exemptionalism Paradigm (HEP), and limits of growth and balance of nature.

Table 1: Revised NEP Statements

\begin{tabular}{|cl|}
\hline Questions \\
\hline$\checkmark$ & We are Approaching the Limit of the number of people the Earth can \\
$\checkmark$ & Support \\
$\checkmark$ & Humans have the right to modify the natural environment to suit their needs \\
& consequences \\
$\checkmark$ & Human ingenuity will insure that we do not make the earth unlivable \\
$\checkmark$ & Humans are seriously absent environment \\
$\checkmark$ & The earth has plenty of natural recourses if we just learn how to develop \\
$\checkmark$ & them \\
$\checkmark$ & The balance of nature is strong enough to cope with the impacts of modern \\
$\checkmark$ & industrial nations
\end{tabular}




\section{France | Paris | April 19-21, 2019}

\begin{tabular}{|ll}
$\checkmark$ & The so-called ecological crisis facing humankind has been greatly \\
& exaggerated \\
$\checkmark$ & The earth is like a spaceship with very limited room and resources \\
$\checkmark$ & Humans were mean to rule over the rest of nature \\
$\checkmark$ & The balance of nature is very delicate and easily upset \\
$\checkmark$ & Humans will eventually learn enough about how nature works to be able to \\
& control it \\
$\checkmark$ & If things continue on their present course, we will soon experience a major \\
& ecological catastrophe
\end{tabular}

Source: Dunlap et al.(2000)

The seven even items, if agreed to by a respondent to represents endorsed by the Dominant Social Paradigm (DSP) the eight odd items if agreed by a respondent are meant to endorsement of New Environmental Paradigm (NEP).

Over the past 30 years researchers are examined various hypotheses and models using NEP to measure for environmental attitudes. There has been little researches in tourism in the context of NEP. However previous studies found and examined relationship between NEP and tourism related environmental behaviours. According to Wearing et al.(2002) environmental concern was not significantly related to environmental purchasing behaviour. Moreover there is no significant difference in ecological behaviour existing being eco-tourist (Wurzinger and Johansson, 2006). However, NEP has found close relationships with place preferences and motivational factors (Kim Hyoung-Gon, Borges and Chon Jin-Hyung, 2006; Uysal et al, 1994).

Lee Hoo-Suk and Oh Min-Jae (2012) categorized NEP to three factors: nature and balance, limitations of growth, and human domination in addition Shen and Chiou (2014) also factorized NEP to limit growth, anti-human centre, balance of nature, exempt natural restrictions, environmental crisis.

\section{Methodology}

For the development of four hypotheses previous studies with existing empirical findings and theories which are related to New Ecological Paradigm and environmental responsible behaviour were taken as reference. The term environmental concern is employed and has positive effect on subjective norm. In another study by Lee Hoo-Suk (2013), Shen and Chiou (2014), they found there is positive effect of New Ecological Paradigm on attitude.

Environmental attitudes were measured with the revised NEP scale. Among 15 statements from revised NEP scale Dunlap et al.(2000), 9 statements used in this study. Respondents were asked 


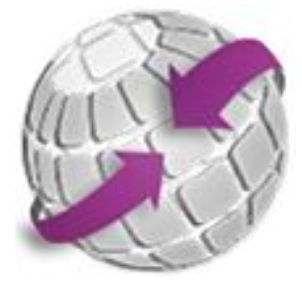

$6^{\text {th }}$ International Conference on New Ideas in Management, Economics and Accounting

\section{France | Paris | April 19-21, 2019}

to rate the extent to which they agreed or disagree with the statements on 5 point Likert scale $(1=$ strongly disagree to $5=$ strongly agree $)$.

This study is based on data from online survey (Google Survey) conducted during 2018 June 1 to June 19. Trekkers from various part of the Republic of Korea are asked online (in various trekking groups in social networking) about their trekking behaviours. Self-administered questionnaires adopted from previous literatures were translated and distributed to 50 participants for pilot study. A total of 300 questionnaires were collected, but 77 questionnaires were rejected since the responses were not suitable for our analysis. Thus, 223 questionnaires were accepted for the analysis. Frequency analyses, exploratory factor analysis, reliability analysis using statistical tools were run by SPSS24.0, and confirmatory factor analysis and structural equation modelling analysis were run by AMOS22.0.

\section{Findings}

Among the 223 respondents, the gender distribution of the respondents was quite balanced; $133(59.64 \%)$ are male and $90(40.36 \%)$ are female. The dominant age group of the respondents is 45 to 54 years old $(29.15 \%)$, followed by 25 to 34 years old $(26.91 \%), 35$ to 44 years old (20.18\%), more than 55(17.04\%), and under 25 years old $(6.73 \%)$. In terms of the education level, 91 respondents $(40.81 \%)$ with the undergraduate degree; 81 respondents $(36.32 \%)$ had a graduate degree; 25 participants $(11.21 \%)$ with college degree; and 21 respondents $(9.42 \%)$ with high school degree; and 5 participants $(2.24 \%)$ with others degree. Respondents having monthly income more than 5001 thousands are 57(25.56\%) followed by monthly income less than 2000 thousands were 50(22.42\%); and 2001 to 3000 and 4000 to 5000 were similar 42 and 43 respectively and lesser number of participants have monthly income of 3000 to $4000(13.90 \%)$. While focusing the respondent's accompany, 54(24.22\%) of the overall participant were with friends, whereas $47(21.08 \%)$ were alone, $45(20.18 \%)$ were with spouse, $39(17.49 \%)$ were with family, 38(17.04\%) were with others. Moreover, the result about tracking time showed that 74 people of the total respondent $(33.18 \%)$ were did more than 3hours, and 70 participants $(31.39 \%)$ were 1 to 2 hours; 41 participants $(18.39 \%)$ were 2 to 3 hours, and 38 participants (17.04\%) were under 1 hour.

The result of the exploratory factor analysis, is elaborated and presented. Three parts were arranged for the exploratory factor analysis, and the KMO value in each part was higher than .73, which turned out that the data was appropriate for the proposed statistical process of factor analysis. Exploratory factor analyses of NEP, all of 9 variables were retained. The total of variance explained is $59.485 \%$ and the KMO value is .764 with the significant value of Bartlett Test of Sphericity at 0.000 level (sig. = .000). The eigenvalue of each factor was more than 1.0; and four factors were extracted and labelled with the NEP scale names as human interfere and 


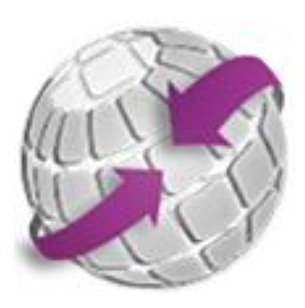

\section{$6^{\text {th }}$ International Conference on New Ideas in Management, Economics and Accounting}

\section{France | Paris | April 19-21, 2019}

eco-crisis (23.796\% variance), limitations of earth resources (18.322\% variance), human domination to earth resources ( $17.367 \%$ variance).

In this study, the results of the reliability of each factor were as follows: human interfere and eco-crisis was .702; limitations of earth resources was .571; human domination to earth resources was .663; subjective norm was .900; and attitude was.843. Based on the criterion of reliability analysis, which is stated that the internal consistency reliability with 0.57 or higher means a high level of accuracy degree, thus, those variables and factors are reliable.

Table 2: Exploratory factor analysis, Reliability analysis and Confirmatory factor analysis

\begin{tabular}{|c|c|c|c|c|c|c|c|c|}
\hline Factor & Question & FL & $\begin{array}{l}\% \text { of } \\
\text { Variance }\end{array}$ & SRW & t-value & SMC & $\mathrm{CR}$ & AVE \\
\hline \multirow{3}{*}{$\begin{array}{c}\text { Human } \\
\text { Interfere and } \\
\text { Eco-Crisis }\end{array}$} & Q1 & .767 & \multirow[t]{4}{*}{23.796} & .639 & $6.353 * * *$ & .408 & \multirow[t]{4}{*}{.796} & \multirow[t]{4}{*}{.497} \\
\hline & Q2 & .693 & & .648 & N/A & .420 & & \\
\hline & Q3 & .680 & & .531 & $5.786 * * *$ & .282 & & \\
\hline$(\alpha=.702)$ & Q4 & .654 & & .706 & $6.525 * * *$ & .498 & & \\
\hline \multirow{3}{*}{$\begin{array}{l}\text { Limitations of } \\
\text { Earth } \\
\text { Resources }\end{array}$} & Q5 & .760 & \multirow[t]{3}{*}{18.322} & .541 & $5.295 * * *$ & .292 & \multirow[t]{3}{*}{.686} & \multirow[t]{3}{*}{.422} \\
\hline & Q6 & .758 & & .603 & $\mathrm{~N} / \mathrm{A}$ & .363 & & \\
\hline & Q7 & .592 & & .531 & $5.287 * * *$ & .282 & & \\
\hline \multirow{2}{*}{$\begin{array}{c}\text { Human } \\
\text { Domination to } \\
\text { Earth } \\
\text { Resources }\end{array}$} & Q8 & .846 & \multirow[t]{3}{*}{17.367} & .755 & $4.488 * * *$ & .570 & \multirow[t]{3}{*}{.657} & \multirow[t]{3}{*}{.490} \\
\hline & Q9 & .841 & & .663 & N/A & .440 & & \\
\hline$(\alpha=.663)$ & & & & & & & & \\
\hline \multirow[t]{3}{*}{ Attitude } & Q10 & .853 & \multirow[t]{3}{*}{26.567} & .781 & $\mathrm{~N} / \mathrm{A}$ & .610 & \multirow[t]{3}{*}{.932} & \multirow[t]{3}{*}{.820} \\
\hline & Q11 & .823 & & .731 & $11.603^{* * *}$ & .534 & & \\
\hline & Q12 & .806 & & .858 & $10.962 * * *$ & .736 & & \\
\hline \multicolumn{9}{|c|}{$\mathrm{KMO}=0.825$, Bartlett Test of Sphericity $=953.467, \mathrm{df}=36, \mathrm{P}=0.000$, Cumulative $\%=73.455 \%$} \\
\hline \multicolumn{9}{|c|}{$\begin{array}{l}\mathrm{X}^{2} / \mathrm{df}=1.329(202.029 / 152), \mathrm{p}=.004, \mathrm{GFI}=.923, \mathrm{RMSEA}=.039, \mathrm{RMR}=.031, \mathrm{NFI}=.906, \mathrm{TLI}=.964, \\
\quad \mathrm{CFI}=.974, * * * \mathrm{p}<.001\end{array}$} \\
\hline
\end{tabular}


Confirmatory factor analysis was employed to assess the measurement model with maximum likelihood. As a result of scale purification, the measurement model fit the data adequately. The model fit statistics was as follows: $\mathrm{X} 2 / \mathrm{df}=1.329(202.029 / 152), \mathrm{p}=.004$, GFI=.923, RMSEA[90\% CI] $=.039[.023 ; .052]$, RMR $=.031$, NFI $=.906$, TLI $=.964$ and $\mathrm{CFI}=.974$. As can be seen in Table 4, all loadings were significant $(\mathrm{p}<.001)$ and loaded on their underlying variables (Anderson and Gerbing, 1988).

Convergent validity refers to weather the variables are highly converged with their specific latent construct (Amin et al., 2016). Convergent validity can be examined with two ways. One is by examining all standard factor loading, in which factor loading should be greater than 0.5 , and all the loadings should be statistically significant at the level of $p<.001$. The other way is to examine AVE and CR values and these values should exceed 0.5(Fornell and Larcker, 1981) and 0.7 respectively. Findings of this study shows that standard factor loadings were ranged from .592 to .939 , and all the loadings were statistically significant at the level of $\mathrm{p}<.001$. Thus, convergent validity for the measurement model was confirmed.

The results of structural model estimation are shown in Fig. 1. The results demonstrate a satisfactory model fit: $\mathrm{X} 2 / \mathrm{df}=1.353(216.469 / 160), \quad \mathrm{p}=.002, \quad \mathrm{GFI}=.917$, RMSEA $=.040[.025 ; .053]$, RMR=.036, NFI=.900, TLI=.962 and CFI=.971(Table 7). As presented in Fig. 2, the path coefficients from New Ecological Paradigm to subjective norm ( $\beta$ $=.455$, C.R. $=2.696)$ and attitude $(\beta=.724$, C.R. $=3.311)$.

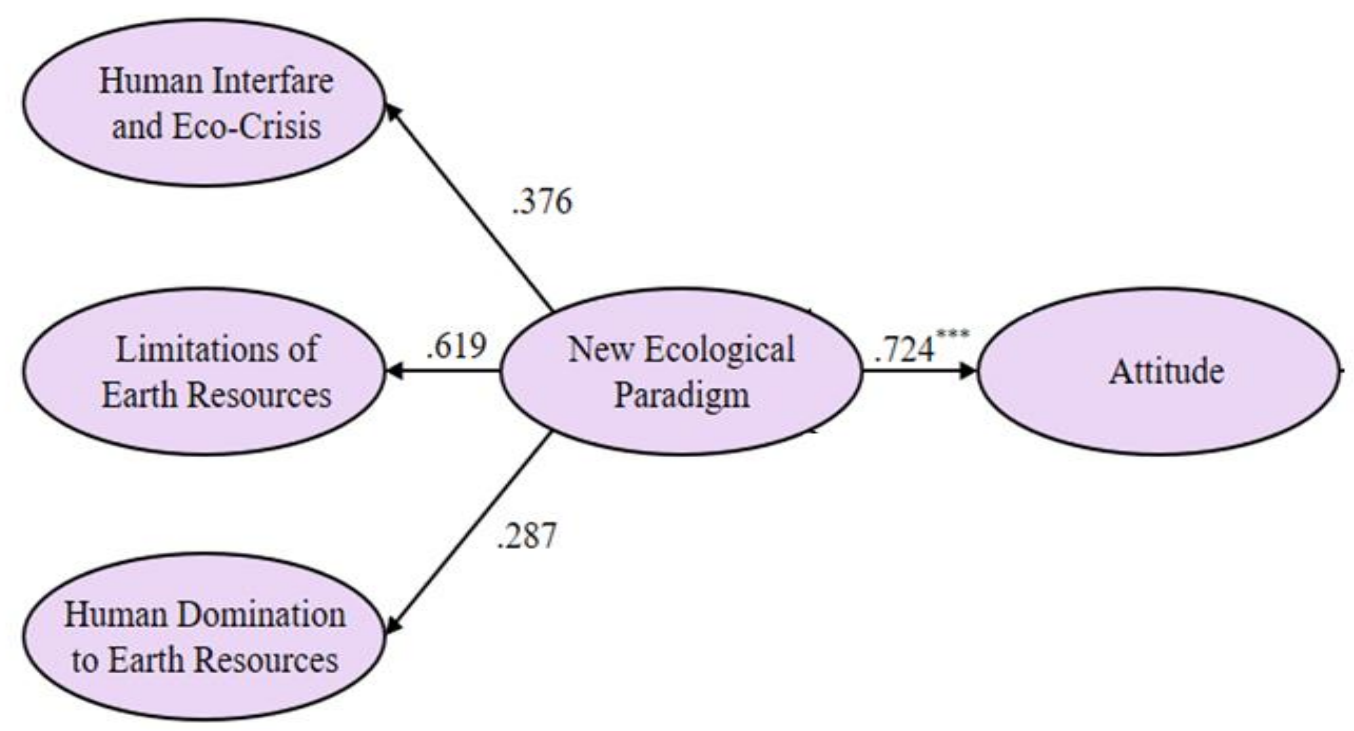

Fig. 1: Results of the model 


\section{Conclusions}

The environmental concern is pretty sensitive these days. Various sectors are aware of harming environment and expect less destruction on nature and surrounding while having their activities. This study studied environmental concern of trekkers and their environmental friendly trekking intention. The results shows people who go on trek are concerned about nature or environment and their attitude towards environment is positive. Most of the trekkers were aware of destruction on environment while trekking.

New Ecological Paradigm to attitude is accepted. It is believed that people who loves trekking or who goes on regular trek think environment is important and have an idea of environmental conservation. More over trekkers are more positive, friendly and have attractive personality. People who go on trek think that environment friendly trekking is positive, praiseworthy and worthwhile. These results are consistent with results of study by Shen and Chiou (2014).

The study of environmental friendly trekking attitudes is quite interesting. Moreover there are very few researches employing New Ecological Paradigm (NEP). This study analysed environmental attitudes of trekkers using NEP towards environment-friendly trekking. This makes study quite new in tourism and trekking research. So it is a very useful resource in academic research, environmental protection policy, tourism research focused on trekking and hiking activities. While talking about results of this most of the trekkers are aware of present condition of environment and were worried about degradation of ecological situation of earth. The main limitations of this study are geographical because respondents are Korean and survey was conducted in Korea. This study used online survey which is quite difficult to include trekkers of age more than 50. This is because it is hard to get older generation in internet. For future work this study focused on trekking area of tourism research there may be other sectors for similar kind of research. This study didn't include trekking season, furthermore environmental attitude and behaviour may differ according to trekking season. Future research can include this seasonal factor for trekking.

\section{References}

[1] Amin, M., R. Thurasamy, A. Aldakhil and A. Kaswuri (2016), "The Effect of Market Orientation as a Mediating Variable in the Relationship between Entrepreneurial Orientation and SMEs Performance", Nankai Business Review International, 7(1), 39-59. 


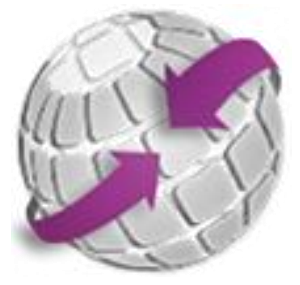

$6^{\text {th }}$ International Conference on New Ideas in Management, Economics and Accounting

\section{France | Paris | April 19-21, 2019}

[2] Anderson, J. C. and D. W. Gerbing (1988), "Structural Equation Modeling in Practice: A Review and Recommended two-step approach”, Psychological Bulletin, 103(3), 411-423.

[3] Ajzen, I. (1985), From intentions to actions: A theory of planned behaviour. In J. Kuhl \& J. Beckmann (Eds.), Action-control: From cognition to behaviour, Berlin, Heidelberg: Springer. 11-39.

[4] Ajzen, I. (1991), "The theory of planned behaviour", Organizational Behaviour and Human Decision Processes, 50(2), 179-211.

[5] Ajzen, I. and M. Fishbein (1980), Understanding Attitudes and Predicting Social Behaviour, New York, Upper Saddle River: Prentice-Hall, 130-147.

[6] Ajzen, I. and T. J. Madden (1986), "Prediction of Goal-Directed Behaviour: Attitudes, Intentions, and Perceived Behavioural Control", Journal of Experimental Social Psychology, 22, 453-474.

[7] Arcury, T. A. (1990), "Environmental Attitudes and Environmental Knowledge”, Human Organization, 49, 300-304.

[8] Arcury, T. A., T. P. Johnson and S. J. Scollay (1986), "Ecological Worldview and Environmental Knowledge: The "New Environmental Paradigm"”, Journal of Environmental Education, 17, 35-40.

[9] Biljana, J., T. Cornwell and D. Mather (2002), "Exploring the Usefulness of an Ecotourism Interest Scale", Journal of Travel Research, 40, 259-69.

[10] Buttel, F. H. (1987), "New Directions in Environmental Sociology", Annual Review of Sociology, 13(1), 465-488.

[11] Caron, J. A. (1989), "Environmental Perspectives of Blacks: Acceptance of the "New Environmental Paradigm"”, Journal of Environmental Education, 20, 21-26.

[12] Catton, W. R. and R. E. Dunlap (1980), “A New Ecological Paradigm for PostExuberant Sociology", American Behavioural Scientist, 24, 15-47.

[13] Cho, Won-Seb (2014), “The Study about Behaviour Intention of Coffee Shop by Using Theory of Extended Planned Behaviour", International Journal of Tourism Management and Sciences, 28(6), 161-179.

[14] Dunlap, R. E. and K. D. Van Liere (1978), “The "New Environmental Paradigm”", The Journal of Environmental Education, 9(4)

[15] Dunlap, R. E., K. D. Van Liere, A. G. Mertig and R. E. Jones (2000), "Measuring Endorsement of the New Ecological Paradigm: A Revised NEP Scale", Journal of Social Issues, 56(3), 425-442 


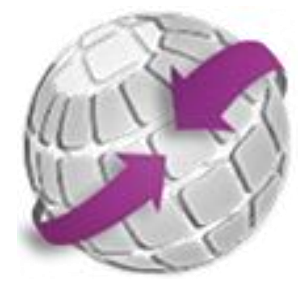

$6^{\text {th }}$ International Conference on New Ideas in Management, Economics and Accounting

\section{France | Paris | April 19-21, 2019}

[16] Edgell, M. C. R. and D. E. Nowell (1989), "The New Environmental Paradigm Scale: Wildlife and Environmental Beliefs in British Columbia", Society and Natural Resources, 2, 285-296.

[17] Fishbein, M. and I. Ajzen (1975), Belief, attitude, intention, and behaviour: An introduction to theory and research. Reading, MA, Boston: Addison-Wesley, 335-384.

[18] Formica, S. and M. Uysal (2008), "Segmentation of Travelers Based on Environmental Attitudes", Journal of Hospitality \& Leisure Marketing, 9(3), 35-49.

[19] Fornell, C. and D. F. Larcker (1981), "Evaluating Structural Equation Models with Unobservable Variables and Measurement Error", Journal of Marketing Research, 18(1), $39-50$.

[20] Furman, A. (1998), "A Note on Environmental Concern in a Developing Country", Environment and Behaviour, 30, 520-534.

[21] Goh, E., B. Ritchie and J. Wang (2017), "Non-Compliance in National Parks: An Extension of the Theory of Planned Behaviour Model with Pro-Environmental Values", Tourism Management, 59, 123-127.

[22] Grybovych, O., A. Cela, Y. Inui and S. V. Lankford (2005), “An Exploratory Study of Environmental Values and Beliefs of Japanese Adventure Tourists in Hawaii", e-Review of Tourism Research, 3(2), 23-30.

[23] Heberlein, T. (1989), “Attitudes and Environmental Management”, Journal of Social Issues, 45, 37-57.

[24] Jang, Seo-Yeon, Jin-Young Chung and Yeong-Gug Kim (2015), "Effects of Environmentally Friendly Perceptions on Customers' Intentions to Visit Environmentally Friendly Restaurants: An Extended Theory of Planned Behaviour", Asia Pacific Journal of Tourism Research, 20(6), 599-618.

[25] Kim, Bo-Kyung. and Jeong-Hee Noh (2017), "A Study on the Behavioural Adherence of Horse Riding Participants from the Perspective of the Theory of Planned Behaviour", Journal of Tourism Sciences, 41(8), 53-70.

[26] Kim, Hyoung-Gon, M. C. Borges and Jin-Hyung Chon (2006), "Impacts of Environmental Values on Tourism Motivation: The Case of FICA, Brazil”, Tourism Management, 27(5), 957-67.

[27] Lee, Duk-Soon. and Ho-Sung Han (2016), “A Study on the Behaviour Intention of Festival Visitors by using Theory of Planned Behaviour: Focusing on Moderation Effect of Perceived Risk", Tourism Research, 41(4), 205-225.

[28] Lee, Hoo-Suk (2013), “The Influences of Tourists` Environmental Perceptions on Satisfactions and Attitudes -The Case of New Environment Paradigm of Tourists to Slow 


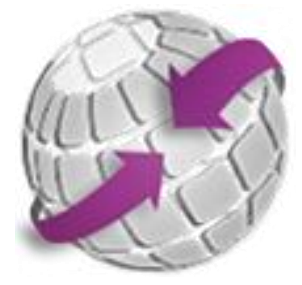

$6^{\text {th }}$ International Conference on New Ideas in Management, Economics and Accounting

\section{France | Paris | April 19-21, 2019}

city(Joan in Namyangju)-", International Journal of Tourism Management and Sciences, 28(3), 189-204.

[29] Lee, Hoo-Suk and MIn-Jae Oh (2012), “A Methodology Logical Discussion on the Classification of Perception Levels about New Environment Paradigm -The Application of DMZ Tourists Motivation and Loyalty-", International Journal of Tourism Management and Sciences, 27(3), 297-319.

[30] Lee, Won-Hee and G. Moscardo (2005), "Understanding the Impact of Ecotourism Resort Experiences on Tourists' Environmental Attitudes and Behavioural Intentions”, Journal of Sustainable Tourism, 13(6), 546-565.

[31] López-Bonilla, L. M. and J. M. López-Bonilla (2016), "From the New Environmental Paradigm to the Brief Ecological Paradigm: a Revised Scale in Golf Tourism”, Anatolia, 27(2), 227-236.

[32] Luzar, E. J., A. Diagne, C. Gan and B. R. Henning (1995), "Evaluating Nature Based Tourism Using the New Environmental Paradigm", Journal of Agricultural and Applied Economics, 27(2), 544-555.

[33] Meng, B., and Kyuh-Wan Choi (2016), "Extending the Theory of Planned Behaviour: Testing the Effects of Authentic Perception and Environmental Concerns on the SlowTourist Decision-Making Process", Current Issues in Tourism, 19(6), 528-544.

[34] Oh, Min-Jae (2018), "Effect relationship between tourism attractiveness, perceived value, attitude, and behavioural intention of a cultural tourism-oriented traditional market place : Focused on the moderating effect of visiting experience", International Journal of Tourism and Hospitality Research, 32(3), 81-96.

[35] Park, Jae-Jin (2003). Understanding consumer intention to shop online: A model comparison (Doctoral dissertation), Columbia: University of Missouri, 61-99.

[36] Park, Sang-Hyuk, Byung-Taek Park and Jae-Hee Jeon (2017), "Exploring the Competition Preparation Behaviour of Shooting Players Applying Theory of Planned Behaviour(TPB)", Sport Science, 34(2), 39-46.

[37] Perugini, M. and R. Bagozzi (2001), “The Role of Desires and Anticipated Emotions in Goal-Directed Behaviours: Broadening and Deepening the Theory of Planned Behaviour", British Journal of Social Psychology, 40(1), 79-98.

[38] Perugini, M. and R. Bagozzi (2004), “The Distinction Between Desires and Intentions", European Journal of Social Psychology, 34(1), 69-84.

[39] Pienaar, E., D. Lew and K. Wallmo (2015), "The Importance of Survey Content: Testing for the Context Dependency of The New Ecological Paradigm Scale", Social Science Research, 51, 338-349. 


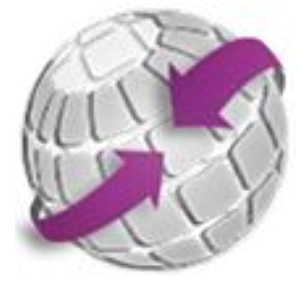

$6^{\text {th }}$ International Conference on New Ideas in Management, Economics and Accounting

\section{France | Paris | April 19-21, 2019}

[40] Ryan, S. and A. Carr (2010), Applying the bio-psychosocial model to the management of rheumatic disease. In: Dziedzic K, Hammond A, eds. Rheumatology: Evidence-Based practice for physiotherapists and occupational therapists, Edinburgh: Churchill Livingstone, 63-75.

[41] Ryu, Jae-Sook and Seung-Kon Lee (2010), “A Study on The Nature-Oriented Tourism Attitude According to The Environmental Perception of Olle-gil Visitors -Focused on the New Environmental Paradigm(NEP) Scale-”, Jorunal of Photo Geography(Sajin Chiri), 20(3), 139-150.

[42] Schwartz, E. S. (1997), "The Stochastic Behaviour of Commodity Prices: Implications for Valuation and Hedging”, Journal of Finance, 52, 923-973.

[43] Shen, S. T. and H. Y. Chiou (2014), “The Factors to Influence Staff's Intention to Adopt Environmental Behaviour in Green University: An Example of Green University in North Taiwan", Journal of Design Science, 17(1), 71-90.

[44] Stern, P. C., T. Dietz and L. Kalof (1993), "Value Orientations, Gender, and Environmental Concern”, Environment and Behaviour, 25(5), 322-348.

[45] Taskin, O. (2009), "The Environmental Attitudes of Turkish Senior High School Students in the Context of Postmaterialism and the New Environmental Paradigm", International Journal of Science Education, 31(4), 481-502.

[46] Taye, F. A., S. E. Vedel and J. B. Jacobsen (2018), “Accounting for Environmental Attitude to Explain Variations in Willingness to Pay for Forest Ecosystem Services Using The New Environmental Paradigm", Journal of Environmental Economics and Policy, 7(4), 420-440.

[47] Uysal, M., C. Jurowski, F. Noe and C. McDonald (1994), "Environmental Attitude by Trip and Visitor Characteristics", Tourism Management, 15(4), 284-94.

[48] Vining, J. and A. Ebreo (1992), "Predicting Recycling Behaviour from Global and Specific Environmental Attitudes and Changes in Recycling Opportunities", Journal of Applied Social Psychology, 22, 1580-1607.

[49] Warshaw, P. R. and F. D. Davis (1985), "Disentangling Behavioural Intention and Behavioural Expectation”, Journal of Experimental Social Psychology, (21), 213-228.

[50] Wearing, S., S. Cynn, J. Ponting and M. McDonald (2002), "Converting Environmental Concern into Ecotourism Purchases: A Qualitative Evaluation of International Backpackers in Australia", Journal of Ecotourism, 1(2), 133-148.

[51] Woo, Eun-Ju and Yeong-Gug Kim (2018), "The Effect of Corporate Social Responsibility(CSR) on behaviour intension based on Extended theory of Planned behaviour: A case of Starbucks Coffee", Journal of Tourism Management Research, 84, 23-45. 


\section{France | Paris | April 19-21, 2019}

[52] Wurzinger, S. and M. Johansson (2006), "Environmental Concern and Knowledge of Ecotourism among Three Groups of Swedish Tourists", Journal of Travel Research, 45, 217-26.

[53] Yim, Hui-Rang and Hak-Seon Kim (2016), "Research Articles: The Study of Behavioural Intention of Environmental Friendly agricultural Products choice in Consumer by Using Theory of Planned Behaviour", Journal of Foodservice Management, 19(1), 201221.

[54] Zografos, C. and D. Allcroff (2007), "The Environmental Values of Potential Ecotoursts: A Segmentation Study", Journal of Sustainable Tourism, 15(1), 44-66. 